\title{
Effect of Epidermal Growth Factor on Lung Maturation in Fetal Rabbits
}

\author{
WILLIAM Z. CATTERTON, MARILYN B. ESCOBEDO, WILLIAM R. SEXSON, MARY E. GRAY, \\ HAKAN W. SUNDELL, AND MILDRED T. STAHLMAN
}

\author{
Department of Pediatrics, Medical College of Georgia, Augusta, Georgia (W.Z.C.); Department of Pediatrics, \\ University of Texas, Health Science Center at San Antonio, San Antonio, Texas (M.B.E.); United States Air Force, \\ Scott AFB, Illinois (W.R.S.); Departments of Pathology (M.E.G.) and Pediatrics (H.W.S., M.T.S.), Vanderbilt \\ University School of Medicine, Nashville, Tennessee USA
}

\section{Summary}

Injection of epidermal growth factor (EGF) into 24-day rabbit fetuses ( $5 \mu \mathrm{g}$, im or ip) induced accelerated maturation of the lung. On sacrifice at day 27 , there was greater distensibility and stability on deflation associated with the appearance of a complement of type II cells approaching that of the rabbit at term. EGF treatment had no demonstrable effect on body weight or lung weight in this group of animals. Saline-injected control fetuses were not affected significantly.

\section{Speculation}

EGF is capable not only of promoting epithelial cell growth but also differentiation in the fetal rabbit lung. It may be an important hormone in the maturation of the lung and capable of protecting the prematurely delivered fetus against the development of hyaline membrane disease.

EGF is a biologically active polypeptide first described in 1962 by Cohen (6), who observed that the daily injection of an extract of male mouse submaxillary gland into immature mice resulted in precocious tooth eruption and eye opening. Subsequent analysis of the salivary gland extract revealed that the biologically active component was a heat-stable, nondialyzable, single polypeptide chain of 53 amino acid residues with a molecular weight of 6045 daltons, as determined by amino acid composition (21). The biologic effects of EGF have been shown to be primarily those of generalized epithelial grow:h and keratinization. These effects of mouse-derived EGF (mEGF) have been demonstrated not only in the mouse and rat, but also in other species such as cultured chick embryo skin (7), human fibroblasts (8), and both chick and human embryo cornea (18). Recently, it has been demonstrated that EGF is also present in the human and that human EGF, when tested in organ culture systems, appeared to act in a manner identical to that of mEGF (19).

In 1975, it was proposed that if EGF is a normal fetal growth hormone, it might also be capable of stimulating pulmonary epithelial cell growth. It was shown that the constant infusion of EGF into fetal lambs for 3-5 days stimulated epithelial growth in many sites, including upper and lower airways. In addition, EGF appeared to afford protection against the development of hyaline membrane disease when given in utero at 123-130 days of gestation (20), which suggested that cell differentiation was stimulated in addition to cell growth.

The present study was undertaken to evaluate the possible role of EGF on the maturation of lung epithelium in the fetal rabbit when administered to the fetus 7 days before term. Lung maturation was assessed by both morphologic and functional measurements.

\section{MATERIALS AND METHODS}

Ten New Zealand White does were mated so that the onset of pregnancy was known to within a 4-hr time period. On the 24th day of a 31-day term gestation, the does were anesthetized using up to $25 \mathrm{mg}$ sodium pentobarbital $/ \mathrm{kg}$ iv as an initial dose, and up to $10 \mathrm{mg}$ sodium thiopenthal $/ \mathrm{kg}$ iv during the course of the operation. Laparotomy was performed, the gravid uterus was exposed and two to three fetuses lying directly under the abdominal incision were selected randomly. To minimize handling, no attempt was made to identify the uterine positions of the fetuses at this time. Fetuses were injected im or ip directly through the uterine wall with $5 \mu \mathrm{g}$ purified $\mathrm{mEGF}$ in saline mixed with barium sulfate or with an equal volume of saline mixed with barium sulfate. The dosage of $5 \mu \mathrm{g}$ was chosen as one which produced minimal but demonstrable hyperplasia of the esophageal epithelium in fetal rabbits of this gestational age. A dose of $10 \mu \mathrm{g} \mathrm{mEGF}$ had earlier been found to be lethal in four of five injected fetuses. The barium sulfate served as a radiopaque marker for subsequent radiographic identification of injected fetuses.'The EGF and saline-injected fetuses were differentiated by alternately marking either the EGF or saline-injected animal with a silk suture taken in the outer uterine wall. The abdominal incision was then closed.

On day 27 of gestation, the does were anesthetized with thiopenthal, viable fetuses were removed from the uterus, and ligatures were tied around the sac and fetal neck to prevent ventilation. Fetuses were killed with $25 \mathrm{mg}$ thiopenthal ip, each fetus was separated from its placenta and sac, blotted dry and weighed, its uterine position identified, and a radiograph taken. The EGF and saline-injected fetuses were identified, and a noninjected fetus of comparable weight and uterine position was selected as an untreated control.

\section{FUNCTIONAL STUDIES}

Cannulation of the trachea of each injected fetus and of the noninjected control fetus was done. With the chest wall intact, deflation pressure-volume measurements $(\mathrm{P}-\mathrm{V})$ were performed as previously described (1). Since more mature lungs are known to rupture at a peak water pressure of $40 \mathrm{~cm}$ and above, $35-40 \mathrm{~cm}$ water pressure was the selected peak pressure for these P-V studies (11). Evidence of lung distention was obvious on inspection, since the thin chest wall allowed direct observation of the degree of lung expansion. In order to eliminate the effects of differences in lung size, peak distensibility was described as the volume of air $(\mathrm{ml})$ retained per gram of lung weight at a distending pressure of 35 $\mathrm{cm} \mathrm{H}_{2} \mathrm{O}\left(\mathrm{V}_{\max } / \mathrm{g}\right)$ and the deflation volumes were recorded as a percentage of the total lung capacity. These values for each group of fetuses were analyzed in pairs by the Student $t$ test. After completion of these functional measurements, the lungs were removed intact and weighed. 


\section{MORPHOLOGIC STUDIES}

Light and electron microscopic studies were made on lungs of the EGF and saline-injected fetuses and the noninjected control fetuses from 8 of the 10 experiments described above. Since the fetal lungs were not fixed until after the functional studies were completed, preparation of tissues was not optimal.

Blocks of tissue were taken from each lung and fixed in Gendre's fluid for light microscopy. Tissue blocks were processed routinely in an Auto-technicon (The Technicon Co., Chauncey, NY), embedded in Paraplast (Sherwood Medical Industries, St. Louis, $\mathrm{MO}$ ), and sectioned at $3 \mu \mathrm{m}$ on a Microtome (Lab Tek, American Optical Co., Buffalo, NY). All sections were stained with hematoxylin and eosin and by the periodic acid-Schiff technique.

Blocks of tissue from the upper lobes were prepared for electron microscopy. Small blocks were diced into $2 \%$ glutaraldehyde in phosphate buffer ( $\mathrm{pH} 7.2$ ). After $2 \mathrm{hr}$ of fixation, tissue blocks were transferred to $7.5 \%$ phosphate-buffered sucrose and stored at $10^{\circ}$. Blocks to be processed for electron microscopy were postfixed in Millonig's osmium tetroxide (14) for $1-2 \mathrm{hr}$, washed in three 15-min changes of distilled water, dehydrated rapidly in ethanol, and embedded in araldite by Luft's procedure (13). Thin sections were mounted on Formvar-coated grids and stained in uranyl acetate for $4 \mathrm{~min}$ and lead citrate (17) for $2 \mathrm{~min}$. Grids were examined with a Philips 200 or 300 electron microscope. Sections, $1 \mu \mathrm{m}$ in thickness, were obtained at the same time for light microscopic study. These semithin sections were stained with $1 \%$ aqueous toluidine blue.

Alveolar lining cells were counted under oil immersion in the semithin sections stained with toluidine blue, which were obtained from blocks of upper lobe. One hundred to 500 lining cells were counted on at least two different blocks from each fetal lung and the percentage of lining cells containing lamellar inclusion bodies was determined. Data on cell counts were analyzed by pairs by the Student $t$ test. The number of lamellar bodies in individual type II cells was assessed by both light and electron microscopy.

\section{RESULTS}

\section{FUNCTIONAL STUDIES}

Table 1 summarizes the measurements conducted on 11 EGFtreated fetuses, 10 saline-injected controls, and 10 noninjected littermates. Comparison of body weight of fetuses directly injected with saline or EGF is difficult to interpret, since the weight varies with its uterine position (12). Thus, EGF-injected fetuses were compared with saline-injected fetuses matched for position. No significant difference in weight was found. Also the EGF-injected fetuses did not differ significantly from the control-injected fetuses in lung weight, or in lung weight to body weight ratios.

There was an increase in distensibility (expressed as milliliter per gram of lung) at distending pressures of $35 \mathrm{~cm} \mathrm{H}_{2} \mathrm{O}$ in the EGF-treated animals. A mean of $2.35 \mathrm{ml} / \mathrm{gm}$ lung was found in the EGF-treated fetuses as compared to 1.91 in the control salineinjected animals $(P<0.05)$; this represents a greater than $20 \%$ increase. No significant difference was found between salineinjected and noninjected animals.

Figure 1 shows the pooled mean deflation pressure volume values from the EGF-injected, saline-injected, and noninjected fetuses. At pressures of less than $20 \mathrm{~cm} \mathrm{H}_{2} \mathrm{O}$, the lungs of the EGF-treated animals retained a larger volume of air than salineinjected control animals; by using the paired Student $t$ test, the differences were significant at $15(P<0.05), 10(P<0.05), 5(P$ $<0.005)$, and $0 \mathrm{~cm} \mathrm{H}_{2} \mathrm{O}(P<0.005)$. Although the saline-injected fetuses retained larger volumes of air than the noninjected controls, the difference in their mean values was not significant.

\section{MORPHOLOGIC STUDIES}

The lungs of all noninjected control fetuses at 27 days of gestational age were canalicular in structure. Interalveolar septa were thick. Alveolar lining cells were predominantly of one type, an undifferentiated cuboidal cell characterized by a relatively large vesicular nucleus, large pools of glycogen, and a few small mitochondria. Golgi apparatus was not identified. Occasionally, segments of the attenuated peripheral cytoplasm of type I cells could be seen. Identifiable type II cells were rare $(7.9 \%$ of the alveolar lining cells) and usually contained from one to five lamellar inclusion bodies. Invasion of capillaries into close proximity to the alveoli was inconspicuous (Fig. 2).

At 27 days of gestational age, the lungs of the fetal rabbits that received saline, im or ip, on day 24 were morphologically similar to those of the noninjected controls. Although cells containing lamellar inclusion bodies constituted only $10.8 \%$ of the alveolar lining cells, an analysis of the data by pairs (untreated vs. salineinjected control rabbits) indicated that there was a small but

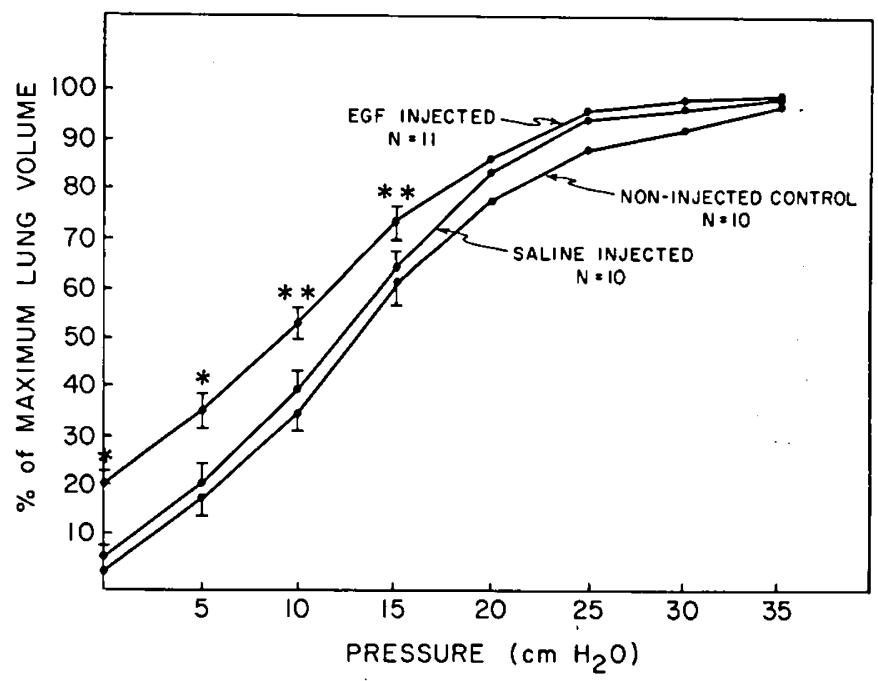

Fig. 1. Relationships of deflation pressures to retention of air in lungs of EGF-injected, saline-injected, and noninjected rabbit fetuses at 27 days of gestation. ${ }^{*} P<0.005 ;{ }^{* *} P<0.05$.

Table 1. Weights and pulmonary distensibilities of noninjected control, saline-injected, and EGF-injected rabbit fetuses at 27 days of gestation

\begin{tabular}{lccccc}
\hline \multicolumn{1}{c}{ Subjects } & $\begin{array}{c}\text { No. of } \\
\text { fetuses }\end{array}$ & $\begin{array}{c}\text { Body weight } \\
(\mathrm{g})\end{array}$ & $\begin{array}{c}\text { Lung weight } \\
(\mathrm{g})\end{array}$ & LW/BW $^{2}$ & $\begin{array}{c}\text { Distensibility } \\
(\mathrm{ml} / \mathrm{g})\end{array}$ \\
\hline EGF-injected & 11 & $24.4 \pm 1.6$ & $0.73 \pm 0.07$ & $0.030 \pm 0.002$ & $2.35 \pm 0.10$ \\
Saline-injected & 10 & $25.7 \pm 1.8$ & $0.79 \pm 0.03$ & $0.031 \pm 0.002$ & $1.91 \pm 0.17$ \\
Noninjected & 10 & $25.7 \pm 1.5$ & $0.77 \pm 0.08$ & $0.031 \pm 0.003$ & $1.73 \pm 0.15$ \\
P $^{4}$ & & NS & NS & NS & $<0.05$ \\
\hline
\end{tabular}

' Values expressed as mean $\pm \mathrm{SE}$.

${ }^{2} \mathrm{LW} / \mathrm{BW}=$ lung weight to body weight ratio.

${ }^{3} \mathrm{ml} / \mathrm{g}=$ volume of air per gram of pulmonary tissue upon inflation to a pressure of $35 \mathrm{~cm} \mathrm{H}_{2} \mathrm{O}$.

${ }^{4} P=$ probability of event occurring by chance (paired $t$ test); EGF-injected compared with saline-injected fetuses. 


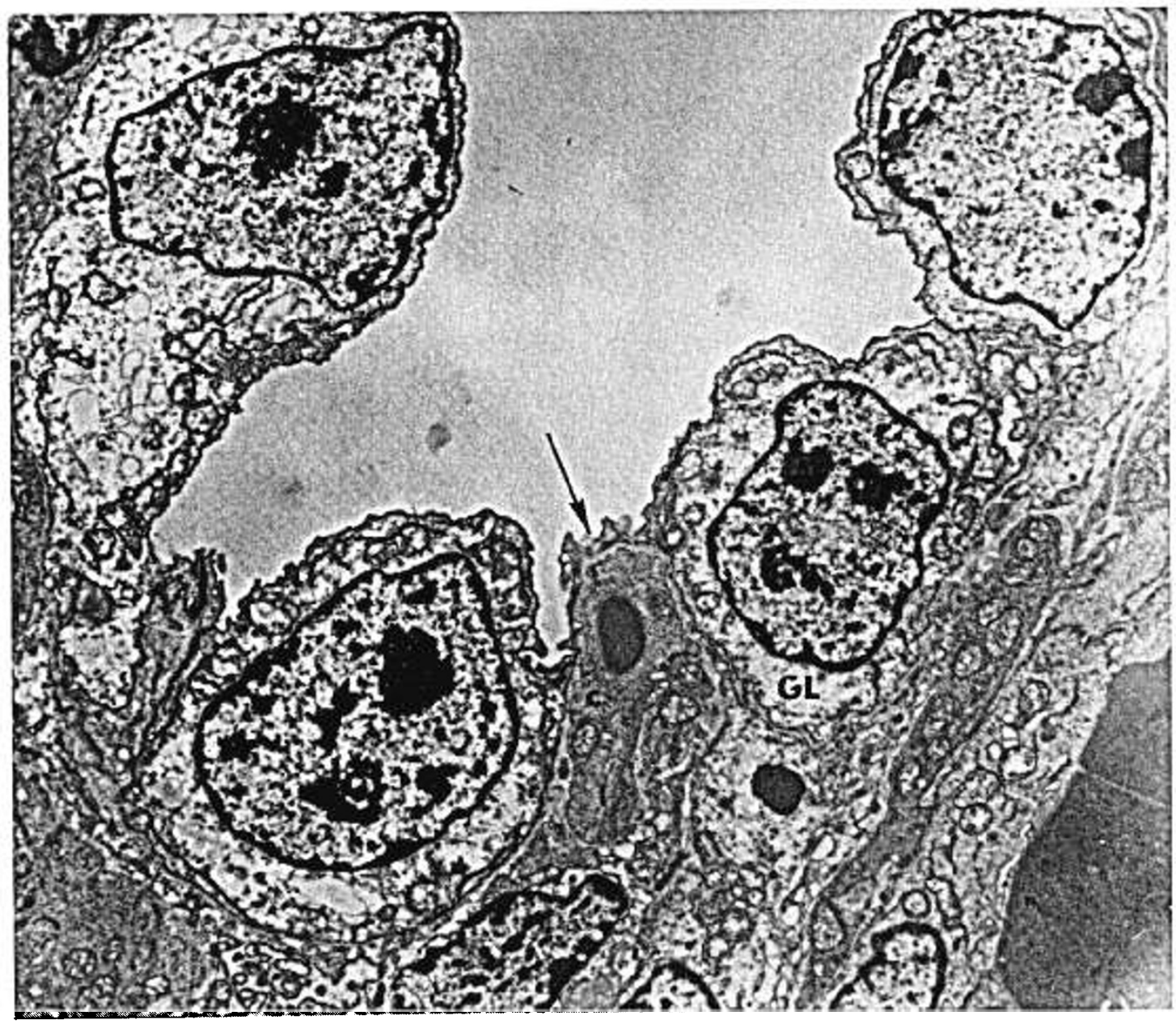

Fig. 2. Electron micrograph of pulmonary alveolus from lung of untreated fetal rabbit at 27 days of gestation. Note the undifferentiated cuboidal lining cells which are characterized by large vesicular nuclei and glycogen spaces (GL). A capillary (c) covered by attenuated type I epithelium (arrow) is seen invading the alveolar lining. There are no type II cells in this alveolus. $\times 6,200$.

significant increase in the number of type II cells in the lungs of the saline-injected fetuses $(P=0.07)$.

All eight fetuses that received EGF, im or ip, on day 24 showed morphologic evidence of accelerated epithelial cell maturation at the time of autopsy on day 27. Interalveolar septa were still relatively thick and there were still many glycogen-filled undifferentiated cuboidal cells. However, there also appeared to be many more areas of attenuated type I cell epithelium stretched over capillaries that were in close approximation to the lining epithelium. In addition, the percentage of type II cells in the lining of the terminal air passages was increased markedly $(30.9 \%)$. The number of lamellar inclusion bodies in individual type II cells also appeared to be increased. Often there were as many as 10 lamellar bodies in a single cell (Fig. 3). Golgi zones were identified in many of the type II cells and multivesicular bodies were seen frequently. There was no evidence of cell proliferation. Analysis of data by pairs (noninjected control vs. EGF-injected fetuses and saline-injected control vs. EGF-injected fetuses) indicated a highly significant increase in the percentage of type II cells in the lungs of the EGF-treated rabbits $(P=0.0001$ and $P=0.0002$, respectively).

\section{DISCUSSION}

The purpose of this study was to determine whether EGF, a hormone known to promote generalized epithelial growth, might have a role in the maturation of pulmonary epithelium in the fetal rabbit when administered to the fetus 7 days before term. Both functional measurements by pulmonary P-V curves and morphologic evaluation were employed to assess the lung maturation.
The fetal rabbit lung undergoes definite changes in the final 6 days of gestation. During this time, pulmonary surface-active material (SAM) becomes evident by direct measurement of surface tension in lung extracts and indirectly by changes in deflation characteristics; and fetal rabbit lung distensibility, measured as volume of air per gram of lung at a peak distending pressure, more than doubles (11). Since such changes can be quantified, they provide means of assessing the degree of pulmonary maturation. Fetuses of 27 days were selected as models because previous work has indicated that lungs at this stage have little or no demonstrable SAM (16), thus induced changes were more likely to be evident.

Quasistatic deflation P-V relationships determined after inflating the lungs revealed that the lungs of EGF-treated fetuses were significantly more distensible at maximum inflation pressures, and significantly more stable on deflation than those of saline-treated controls. Several different investigators have shown such changes to correlate well with other measures of alveolar SAM and to reflect an increase in lung maturation $(2,5)$.

The morphologic studies indicated that the EGF-induced increase in lung stability was associated with accelerated differentiation of alveolar lining cells. This was reflected by an increase in the areas of attenuated type I epithelium covering the capillaries, an increase in the percentage of type II cells in the alveolar lining, and an increase in type II cell lamellar bodies which are considered to be the major source of $\operatorname{SAM}(3,10,15)$.

The appearance of the noninjected control rabbits at 27 days of gestation by both light and electron microscopy agrees well with the description given by Wang et al. (22). The percentage of type II cells in the alveolar lining at 27 days of gestation that we have 


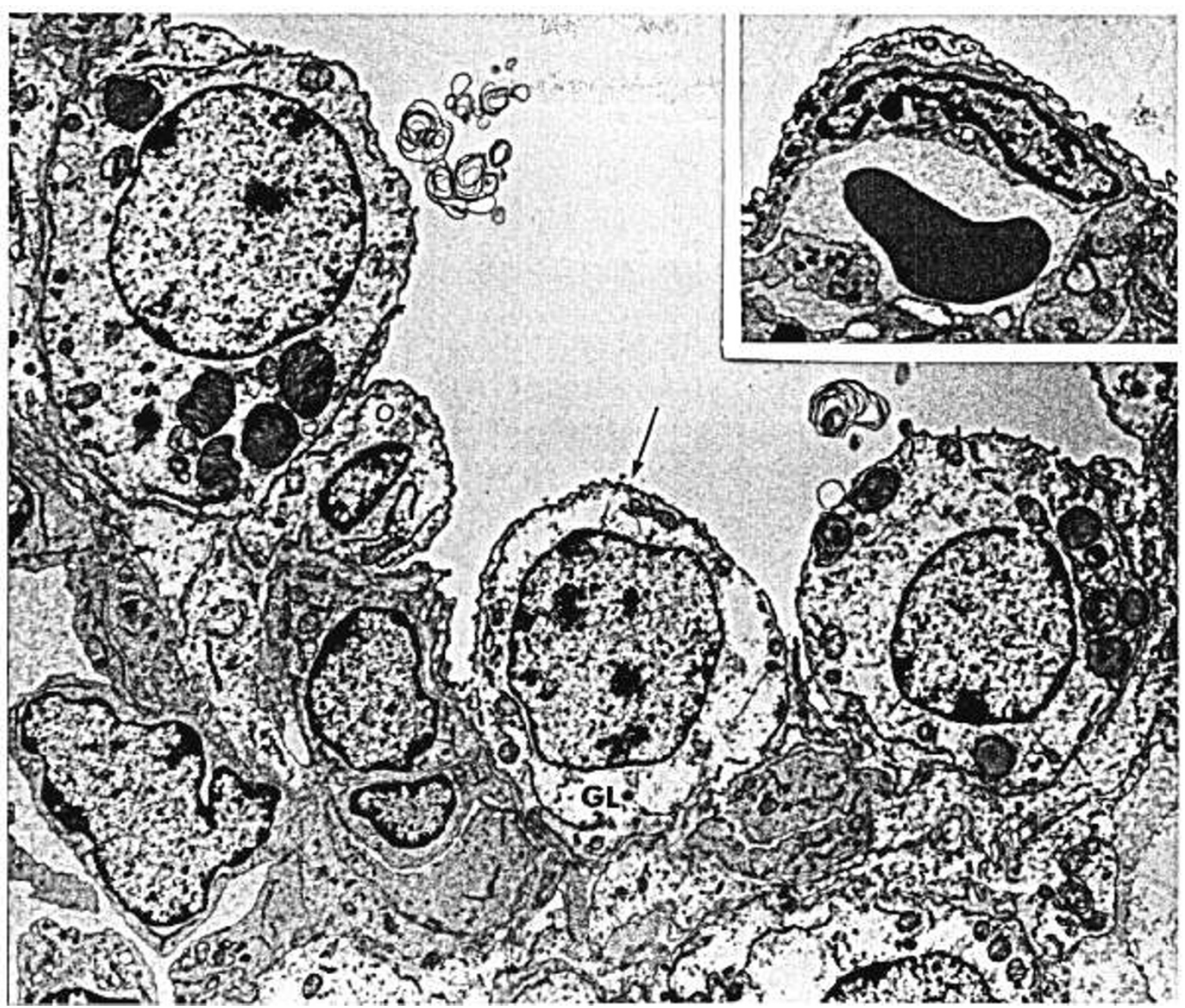

Fig. 3. Electron micrograph of pulmonary alveolus from lung of fetal rabbit at 27 days of gestation that was treated with EGF on day 24 . Note the two type II cells containing numerous lamellar bodies and lamellar material in the alveolus. One of the alveolar lining cells (arrow) is undifferentiated and is similar to those in Figure 2. Inset: Capillary containing erythrocyte and platelet is covered by flattened type I cell epithelium. This portion of alveolar wall was contiguous with the type II cell in the upper left. GL, glycogen space. $\times 6200$.

reported $(7.8 \%)$ is lower than that reported by Wang et al. (16.5\%). This could be due to the method by which our counts were obtained. With light microscopy, even in semithin sections, some cells containing only one or two lamellar bodies could be missed more easily than with electron microscopy. At 29-30 days of gestation in the untreated rabbit fetus, Wang et al. (22) reported a percentage of "near to over 40\%" of type II cells in the alveolar lining. In our EGF-treated fetuses, the large, lamellar inclusionfilled type II cells were easily identified and it appeared that the alveolar lining in these animals at 27 days of gestation had a complement of type II cells (30.9\%) approaching that of the rabbit at term.

EGF treatment had no demonstrable effect on body weight or lung weight in this group of fetal rabbits. EGF, therefore, seems to be able to promote fetal pulmonary epithelial cell growth and differentiation without inhibiting general organ growth. Corticosteroids, which also have been found to accelerate fetal rabbit lung differentiation and maturation, cause a decreased lung weight and a low lung weight to body weight ratio $(4,11)$. This decrease in lung growth has been found to be associated with a slowing of lung cell mitosis in favor of differentiation (4). Thyroxin (23) and prolactin (9) on the other hand also accelerate fetal rabbit lung maturation but without influencing lung weight.

The mechanisms through which EGF exerts its effects on fetal lung maturation is unknown. Sundell et al. (19) showed that EGF infusion in lambs resulted in no elevation of plasma cortisol, estradiol, or thyroxin; thus indicating that the EGF effect is probably not mediated through these endocrine organ products. Further studies are necessary to determine the mechanisms of EGF's effect on lung maturation.

\section{REFERENCES AND NOTES}

1. Avery, M. E., Frank, N. R., and Gribetz, l.: The inflationary force produced by pulmonary vascular distention in excised lungs, the possible relation of this force to that needed to inflate the lungs at birth. J. Clin. Invest.., 38: 456 (1959).

2. Brumley, G. W., Chernick, V., Hodson, W. A., Normand, C.. Fenner, A. and Avery, M. E.: Correlations of mechanical stability, morphology, pulmonary surfactant, and phospholipid content in the developing lamb lung. J. Clin. Invest., $46: 863$ (1967).

3. Buckingham, S., Heinemann, H. O., Sommers, S. C., and McNary, W. F. Phospholipid synthesis in the large pulmonary alveolar cell. Its relation to lung surfactants. Am. J. Pathol., 48: 1027 (1966).

4. Carson, S. H., Taeusch, Jr., H. W., and Avery, M. E.: Inhibition of lung cell division after hydrocortisone injection into fetal rabbits. J. Appl. Physiol., 34: 660 (1973)

5. Clements, J. A., Hustead, R. F., Johnson, R. P., and Gribetz, I.: Pulmonary surface tension and alveolar stability. J. Appl. Physiol., 16: 444 (1961).

6. Cohen, S.: Isolation of a mouse submaxillary gland protein accelerating incisor eruption and eyelid opening in the newborn animal. J. Biol. Chem., 237: 1555 (1963).

7. Cohen, S.: The stimulation of epidermal proliferation by a specific protein (EGF). Dev. Biol., 12: 394 (1965).

8. Cohen, S.: Interaction of epidermal growth factor (EGF) with cultured fibroblasts. Adv. Metab. Disord., 8: 265 (1975).

9. Hamosh, M., and Hamosh, P.: The effect of prolactin on lecithin content of fetal rabbit lung. J. Clin. Invest., 59: 1002 (1977).

10. Kikkawa, G.. Motoyama, E. K., and Cook, C. D.: The ultrastructure of the lung of the lamb. The relationship of osmiophilic inclusions and alveolar lining 
layer to fetal maturation and experimentally produced respiratory distress. Am. J. Pathol., 47: 877 (1965).

1I. Kotas, R. V., and Avery, M. E.: Accelerated appearance of pulmonary surfactant in the fetal rabbit. J. Appl. Physiol., 30: 358 (1971).

12. Kotas, R. V., Fletcher, B. D., Torday, J., and Avery, M. E.: Evidence for independent regulation of organ maturation in fetal rabbits. Pediatrics, 47:57 (1971).

13. Luft, J. H.: Improvements in epoxy resin embedding methods. J. Biophys. Biochem. Cytol., 9: 409 (1961).

14. Millonig, G.: Advantages of a phosphate buffer for OsO, solutions in fixation. J. Appl. Physics, 32: 163 (1961).

15. Morgan, T. E.: Pulmonary Surfactant. N. Engl. J. Med., 284: 1185 (1971).

16. Motoyama, E. K., Orzalese, M. M., Kikkawa, Y., Kaibara, M., Wu, B., Zigas, C. J., and Cook, C. D.: Effect of cortisol on the maturation of fetal rabbit lungs. Pediatrics, 48: 547 (1971).

17. Reynolds, E. S.: The use of lead citrate at high $\mathrm{pH}$ as an electron opaque stain in electron microscopy. J. Cell Biol., 17: 208 (1963).

18. Savage, Jr., C. R., and Cohen, S.: Proliferation of corneal epithelium induced by epidermal growth factor. Exp. Eye. Res., 15: 361 (1973).

19. Starkey, R. H., Cohen, S., and Orth, D. N.: Epidermal growth factor: identification of new hormone in human urine. Science, 189: 800 (1975).

20. Sundell, H., Serenius, F., Barthe, P., Friedman, Z., Kanarek, K., Escobedo, M.,
Orth, D., and Stahlman, M. T.: The effect of EGF on fetal lamb lung maturation. Pediatr. Res., 9: 371 (1975).

21. Taylor, J. M., Mitchell, W. M., and Cohen, S.: Epidermal growth factor. Physical and chemical properties. J. Biol. Chem., 247: 5928 (1972).

22. Wang, N. S., Kotas, R. V., Avery, M. E., and Thurlbeck, W. M.: Accelerated appearance of osmiophilic bodies in fetal lungs following steroid injection. $\mathbf{J}$. Appl. Physiol., 30: 362 (1971).

23. Wu, B., Kikkawa, Y., Orzalesi, M. M., Motoyama, E. K., Kaibara, M., Zigas, C. J., and Cook, C. D.: The effect of thyroxine on the maturation of fetal rabbit lungs. Biol. Neonate, 22: 161 (1973).

24. Dr. Catterton is a recipient of an American Lung Association Training Fellowship.

25. We wish to express special appreciation to Patricia Minton, R.N., and to David Oliver and Rao Gaddipati, Research Assistants, whose help was essential to the completion of this experiment. Appreciation is also expressed to Dr. Stanley Cohen and Dr. David N. Orth for supplying the EGF.

26. This research was supported by Grant HL-14214 from the National Institutes of Health, National Heart, Lung and Blood Institute, Bethesda, MD.

27. Requests for reprints should be addressed to: Department of Pediatrics, Vanderbilt University School of Medicine, Nashville, TN 37232 (USA).

28. Received for publication November 29, 1977.

29. Accepted for publication March 29, 1978 